\title{
Hydrodynamic characteristics of expanded channels with their applications----the state-of-the-art
}

\author{
Edward Ching-Ruey, LUO
}

Department of Civil Engineering, National Chi-Nan University, Nantou, TAIWAN.227 Gan-Cherng St. Taichung 40843, TAIWAN

Email address:

edward.luo@msa.hinet.net(E. C. LUO)

\section{To cite this article:}

Edward Ching-Ruey, LUO.Hydrodynamic Characteristics of Expanded Channels with their Applications----the State-of-the-Art. American Journal of Civil Engineering. Vol. 1, No.1, 2013; pp. 31-40.doi: 10.11648/j.ajce.20130101.15

\begin{abstract}
In this study, analytical-statistical solutions of the characteristics in gradually and abruptly expanded channel flows, such as velocity profile, turbulent shear stress profile and profiles of turbulent kinetic energy, energy dissipation rate, and dispersion coefficient are derived. Then, the comparisons of the analytical results are made with the results of 2-DH with depth-averaged numerical model solution and some experimental results.Good trends and agreements are obtained, and the expanding angletakes an important and relevant role on the main effect of these hydrodynamic items. The quasi-3D flow situation due to the downstream abruptly contracted channel with the upstream abruptly expanded channel is also shown and discussed. In this paper, the new contributions, ideas, clarifications and applications that resulted after the paper was given are presented.
\end{abstract}

Keywords: Velocity Profile, Turbulent Shear Stress, Turbulent Kinetic Energy, Energy Dissipation Rate, Dispersion, Turbulence, Expanded Flow, Hydrodynamics

\section{Introduction}

There exist many practical engineering applications, such as tubular heat exchangers, capillary-tube viscometry, polymer processing, biomedical instruments, thermoforming, various manufacturing processes, fiber spinning, extrusion, injection molding, biomedical instruments, flow of refrigerant, flow control, energy dissipation, sediment treatment, etc., in which the behavior of flow field in the presence of the downstream with the gradual and sudden geometric expansions is important and it is one of the most fundamental phenomenon of study in the field of fluid mechanics with the Newtonian and non-Newtonian flow case being of particular interest. Several investigations have been performed in order to understand the incompressible flow downstream of a channel expansion, which is planar and is normal to the direction of the channel wall. These investigations have been both numerical. With the presence of various dissipative behaviors, investigations into this channel flow allow better understanding of boundary layer separation, re-attachment and recirculation, which are common features in engineering practice.

As the direct result of turbulence generates at the boarders of a free or submerged case inlet jet, the fluid within the jet undergoes both lateral diffusion and deceleration, and at the same time, fluid from the surrounding region is brought into motion in more explicit terms. The difference in velocity between a jet and the region into which it is discharged gives rise to a pronounced degree of instability, and the latter steadily decaying through viscous shear forming energy dissipation rate. In view of the Newtonian principle of motion between action and reaction, moreover, it is realized that deceleration of the fluid in the jet can occur only through simultaneously acceleration of the surrounding fluid, so that the total rate of flow passing through successive sections of the jet actually increases with distance from the outlet. In the cases of $\beta=0^{\circ}, 0^{\circ}<\beta<4.6^{\circ}, \beta \geqq 4.6^{\circ}$ and $\beta=$ $90^{\circ}$, the circulating flow situation happens from the entrance until certain distance downstream. Within the circulation region, convective term, diffusion term, bottom stress, and the dispersion term in 2-D model exist due to the reason for the depth-integrated method from 3-D flow equation. The new velocity profile must be re-derived, and then the analytical turbulent shear stress, turbulent kinetic energy, and energy dissipation rate profiles are shown respectively for different $\beta$ situations. After those procedures, the comparisons between numerical and analytical results are done to express the validity and 
reliability of the analyses.

\section{Governing Equations}

Many turbulence models based on Reynolds-averaged Navier-Stokes equations,such as zero-equation turbulence model, one-equation turbulence model, two-equation turbulence model and Reynolds stress/flux model, have been successfully applied to the simulation of turbulent flows in computational fluid dynamics(CFD). In recent years, the large eddy simulation and direct numerical simulationof turbulent flows have also progressed remarkably. These turbulence modelingtechniques have been gradually applied in the simulation of river flows. However,because the computational domain in natural rivers is very irregular and evenmoveable, the simulation of turbulent flow in rivers is less developed and mostlystays on the level of twoequation turbulence models or simpler ones. For the depthaveraged simulation of river flows, one of the most often used two-equationturbulence models is Rastogi and Rodi's [1] depth-averaged standard k- $\varepsilon$ " turbulence model. In the present study, Chen and Kim's [2] non-equilibrium k- $\varepsilon$ "turbulence model and Yahkot et al's [3] RNG k- $\varepsilon$ " turbulence model, whichare widely used in CFD, are extended to the depth-averaged 2-D simulation ofriver flows. These two k- $\varepsilon$ " turbulence models are compared with other threedepthaveraged turbulence models: the depthaveraged parabolic eddy viscositymodel, the modified mixing length model, and Rastogi and Rodi's depth-averagedstandard $k-\varepsilon "$ model.The depth-integrated continuity and momentum equations of turbulent flow in open channels are :

$$
\begin{gathered}
\frac{\partial \mathrm{h}}{\partial \mathrm{t}}+\frac{\partial(\mathrm{hU})}{\partial \mathrm{x}}+\frac{\partial(\mathrm{hV})}{\partial \mathrm{y}}=0 \\
\frac{\partial}{\partial \mathrm{x}}\left(\mathrm{HU}^{2}\right)+\frac{\partial}{\partial \mathrm{y}}(\mathrm{HUV})+\mathrm{gH} \frac{\partial \xi}{\partial \mathrm{x}}+\frac{\tau_{\mathrm{bx}}}{\rho}-\frac{\partial\left(\mathrm{HT}_{\mathrm{xx}}\right)}{\rho \partial \mathrm{x}}-\frac{\partial\left(\mathrm{HT}_{\mathrm{xy}}\right)}{\rho \partial \mathrm{y}}=0 \\
\frac{\partial(\mathrm{HUV})}{\partial \mathrm{x}}+\frac{\partial\left(\mathrm{HV}^{2}\right)}{\partial \mathrm{y}}+\mathrm{gH} \frac{\partial \xi}{\partial \mathrm{y}}+\frac{\tau_{\mathrm{by}}}{\rho}-\frac{\partial\left(\mathrm{HT}_{\mathrm{xy}}\right)}{\rho \partial \mathrm{x}}-\frac{\partial\left(\mathrm{HT}_{\mathrm{yy}}\right)}{\rho \partial \mathrm{y}}=0
\end{gathered}
$$

wheret is the time; $\mathrm{x}$ and $\mathrm{y}$ are the horizontal Cartesian coordinates; $\mathrm{h}$ is the flowdepth; $\mathrm{U}$ and $\mathrm{V}$ are the depth-averaged flow velocities in $\mathrm{x}$ - and $\mathrm{y}$-directions; zsis the water surface elevation; $g$ is the gravitational acceleration; ${ }^{2}$ is the densityof flow; It should be noted that Eqs. (2) and (3) do not include the dispersion termsthat exist due to the vertical non-uniformity of flow velocity. Their effect is assumed to be negligible in this study, but the treatment of these terms has beenstudied by Flokstra [4], $\mathrm{Wu}$ and Wang and others[5]. andthe turbulent stresses are determined by Boussinesq's assumption:

$$
\begin{gathered}
\tau_{\mathrm{by}}=\rho \mathrm{c}_{\mathrm{f}} \mathrm{U} \sqrt{\mathrm{U}^{2}+\mathrm{V}^{2}} \\
\tau_{\mathrm{by}}=\rho \mathrm{c}_{\mathrm{f}} \mathrm{U} \sqrt{\mathrm{U}^{2}+\mathrm{V}^{2}} \\
\mathrm{c}_{\mathrm{f}}=\mathrm{gn}^{2} / \mathrm{h}^{1 / 3} \\
\mathrm{~T}_{\mathrm{xx}}=2 \rho\left(v+v_{\mathrm{t}}\right) \frac{\partial \mathrm{U}}{\partial \mathrm{x}}-\frac{2}{3} \rho \mathrm{k}
\end{gathered}
$$

$$
\begin{array}{r}
\mathrm{T}_{\mathrm{xy}}=\mathrm{T}_{\mathrm{yx}}=\rho\left(v+v_{\mathrm{t}}\right)\left(\frac{\partial \mathrm{U}}{\partial \mathrm{y}}+\frac{\partial \mathrm{V}}{\partial \mathrm{x}}\right) \\
\mathrm{T}_{\mathrm{yy}}=2 \rho\left(v+v_{\mathrm{t}}\right) \frac{\partial \mathrm{V}}{\partial \mathrm{y}}-\frac{2}{3} \rho \mathrm{k}
\end{array}
$$

Where? is the kinematic viscosity of water; $v_{\mathrm{t}}$ is the eddy viscosity due to turbulence; $\mathrm{k}$ is the turbulence energy. The $\mathrm{k}$ in Eqs. (7), (8) and (9) is dropped whenthe zero equation turbulence models are considered.

\section{Models for Eddy Turbulent Viscosity}

\subsection{Depth-Averaged Parabolic Eddy Viscosity Model}

Averaging the eddy viscosity, which approximately yields a parabolic profile, overthe flow depth, one can obtain the depth-averaged parabolic model for the eddyviscosity:

$$
\begin{gathered}
v_{\mathrm{t}}=\alpha_{\mathrm{t}} \mathrm{U}_{*} \mathrm{~h} \\
\mathrm{U}_{*}=\left[\mathrm{c}_{\mathrm{f}}\left(\mathrm{U}^{2}+\mathrm{V}^{2}\right)\right]^{1 / 2}
\end{gathered}
$$

where $U_{*}$ is the bed shear velocity, and $\alpha_{t}$ is an empirical coefficient. Theoretically, $\alpha_{t}$ should be equal to $\boldsymbol{k}_{/ 6}$, with $\boldsymbol{k}^{\mathrm{b}}$ being the van Karman's constant. However, different values have been given to $\alpha_{t}$, which may be due to the anisotropic features of turbulence structures in horizontal and vertical directions. It is commonly accepted that $\alpha_{t}$ is related to the ratio of channel width and flow depth, having values between 0.3 to 1.0 (Elder [6], Fischer et al [7]).

\subsection{Modified Mixing Length Model}

Eq. (10) is very simple. It is applicable in the region of main flow, but does not account for the influence of the horizontal gradient of velocity. Significant errors may exist when it is applied in the region close to rigid walls. Improvement can be achieved through the combination of Eq. (10) and Prandtl's mixing length theory, which reads:

$$
\begin{gathered}
v_{\mathrm{t}}=\sqrt{\left(\alpha_{0} \mathrm{U}_{*} \mathrm{~h}\right)^{2}+\left(\mathrm{\iota}_{\mathrm{h}}^{2}|\overline{\mathrm{S}}|\right)^{2}} \\
|\overline{\mathrm{S}}|=\left[2(\partial \mathrm{U} / \partial \mathrm{x})^{2}+2(\partial \mathrm{V} / \partial \mathrm{y})^{2}+(\partial \mathrm{U} / \partial \mathrm{y}+\partial \mathrm{V} / \partial \mathrm{x})^{2}\right]^{1 / 2} \\
\iota_{\mathrm{h}}=\kappa \min \left(\mathrm{c}_{\mathrm{m}} \mathrm{h}, \mathrm{y}\right)
\end{gathered}
$$

where $\alpha_{0}$ is an empirical coefficient, set as $\mathbf{k}^{\mathbf{2}} / 6 ; \mathbf{l}_{\mathrm{h}}$ is the horizontal mixing length, with y being the distance to the nearest wall, and $\mathrm{cm}$ anempirical coefficient.

\subsection{Standard $k-\varepsilon "$ Turbulence Model}

Rastogi and Rodi [1] established the depth averaged k- $\varepsilon^{\prime \prime}$ turbulence modelthrough depthintegrating with the 3-D standard $\mathrm{k}-\varepsilon$ " model. The eddy viscosity $v_{\mathrm{t}}$ iscalculated by

$$
v_{\mathrm{t}}=\mathrm{c}_{\mu} \mathrm{k}^{2} / \varepsilon
$$


Where $c_{\mu}$ is an empirical constant. The turbulence energy $\mathrm{k}$ and its dissipationrate " are determined with the following model transport equations:

$$
\begin{aligned}
& \overline{\mathrm{U}} \frac{\partial \overline{\mathrm{k}}}{\partial \mathrm{x}}+\overline{\mathrm{V}} \frac{\partial \overline{\mathrm{k}}}{\partial \mathrm{x}}=\frac{\partial}{\partial \mathrm{x}}\left(\frac{\bar{v}_{\mathrm{t}}}{\sigma_{\mathrm{t}}} \frac{\partial \overline{\mathrm{k}}}{\partial \mathrm{x}}\right)+\frac{\partial}{\partial \mathrm{y}}\left(\frac{\bar{v}_{\mathrm{t}}}{\sigma_{\mathrm{t}}} \frac{\partial \overline{\mathrm{k}}}{\partial \mathrm{y}}\right)+\mathrm{P}_{\mathrm{h}}+\mathrm{P}_{\mathrm{k} v}-\varepsilon \\
& \overline{\mathrm{U}} \frac{\partial \bar{\varepsilon}}{\partial \mathrm{x}}+\overline{\mathrm{V}} \frac{\partial \bar{\varepsilon}}{\partial \mathrm{x}}=\frac{\partial}{\partial \mathrm{x}}\left(\frac{\bar{v}_{\mathrm{t}}}{\sigma_{\varepsilon}} \frac{\partial \bar{\varepsilon}}{\partial \mathrm{x}}\right)+\frac{\partial}{\partial \mathrm{y}}\left(\frac{\bar{v}_{\mathrm{t}}}{\sigma_{\varepsilon}} \frac{\partial \bar{\varepsilon}}{\partial \mathrm{y}}\right)+\mathrm{c}_{1 \varepsilon}\left(\frac{\bar{\varepsilon}}{\overline{\mathrm{k}}}\right) \mathrm{P}_{\mathrm{h}}+\mathrm{P}_{\varepsilon v}-\mathrm{c}_{2 \varepsilon}\left(\frac{\bar{\varepsilon}^{2}}{\overline{\mathrm{k}}}\right)
\end{aligned}
$$

where $\mathrm{P}_{\mathrm{h}}=v_{\mathrm{t}}|\overline{\mathrm{S}}|^{2}, \quad \mathrm{P}_{\mathrm{kv}}=\mathrm{c}_{\mathrm{f}}^{-1 / 2} \mathrm{U}_{*}^{3} / \mathrm{h} ; \quad$ and $\mathrm{c}_{\mu}=0.09$; $\mathrm{c}_{1 \varepsilon}=1.44 ; \mathrm{c}_{2 \varepsilon}=1.92 ; \mathrm{P}_{\varepsilon v}=\mathrm{c}_{\varepsilon \Gamma} \mathrm{c}_{\varepsilon 2} \mathrm{c}_{\mu}^{1 / 2} \mathrm{c}_{\mathrm{f}}^{-3 / 4} \mathrm{U}_{*}^{4} / \mathrm{h}^{2}$ $\sigma_{\mathrm{k}}=1.0 ; \sigma_{\varepsilon}=1.3 ; \mathrm{c}_{\varepsilon \Gamma}=1.8$ to 3.6

\subsection{Non-equilibrium k- $\varepsilon^{\prime \prime}$ Turbulence Model}

Chen and Kim [2] modified the standard k- $\varepsilon^{\prime \prime}$ turbulence model to consider thenon-equilibrium between the generation and dissipation of turbulence. A secondtime scale of the production range of turbulence kinetic energy spectrum is added to the dissipation rate equation, which results in a functional form of coefficient,

$$
\begin{gathered}
\mathrm{c}_{\varepsilon 1}=1.15+\frac{0.25 \mathrm{P}_{\mathrm{h}}}{\varepsilon} . \\
\mathrm{c}_{\mu}=0.09 ; \mathrm{c}_{2 \varepsilon}=1.90 ; \\
\sigma_{\mathrm{k}}=0.8927 ; \sigma_{\varepsilon}=1.15 ;
\end{gathered}
$$

The modified model was called the non-equilibriumk- $\varepsilon$ " turbulence model (Shyy et al [8]), which has been tested in a compressible recirculating flow with improved performance over the standard model. ByusingRastogi and Rodi's [1] depth-averaging approach, the depth-averagednon-equilibrium $\mathrm{k}-\varepsilon^{\prime \prime}$ model can be derived from the 3-D version. The formulationsof $\mathrm{k}$ - and " $\varepsilon$-equations are still the same as Eqs. (16) and (17), with only the modelcoefficients being replaced accordingly.

\subsection{RNG k-E" Turbulence Model}

Yakhot et al [3] re-derived the " $\varepsilon$-equation (17) using the re-normalized group(RNG) theory. One new term was introduced to take into account the highlyanisotropic features, usually associated with regions of large shear, and to modifythe viscosity accordingly. This term was claimed to improve the simulation ac-curacy of the RNG $\mathrm{k}-\varepsilon^{\prime \prime}$ turbulence model for highly strained flow. By analogy tothe above non-equilibrium turbulence model, thedepthaveraged 2-D RNG k- $\varepsilon$ "turbulence model can also be derived, whose k- and " $\varepsilon$-equations are the sameas Eqs. (16) and (17), with the new term being included in the coefficient,

$$
\begin{gathered}
\mathrm{c}_{\varepsilon 1}=1.42-\eta(1-\eta / \eta 0) /\left(1+\beta \eta^{3}\right) \\
\beta=0.015, \eta=|\overline{\mathrm{S}}| \mathrm{k} / \varepsilon, \eta 0=4.38 \\
\mathrm{c}_{\mu}=0.085, \mathrm{c}_{\varepsilon 2}=1.68, \sigma \mathrm{k}=0.7179, \sigma_{\varepsilon}=0.7179
\end{gathered}
$$

\section{Boundary Conditions}

Near rigid wall boundaries, such as banks and islands, the wall-function approach is employed. By applying the log-law of velocity, the resultant wall shear stress $\vec{\tau}_{w}$ is related to the flow velocity $\overrightarrow{\mathrm{V}}_{\mathrm{p}}$ at center $\mathrm{P}$ of the control volume close to the wall, by the following relation:

$$
\begin{gathered}
\vec{\tau}_{\mathrm{w}}=-\lambda \overrightarrow{\mathrm{V}}_{\mathrm{p}} \\
\lambda=\rho \mathrm{c}_{\mu}^{1 / 4} \mathrm{k}_{\mathrm{P}}^{1 / 2} \kappa / \ln \left(\mathrm{Ey}_{\mathrm{P}}^{+}\right)
\end{gathered}
$$

$11.6<\mathrm{y}_{\mathrm{P}}^{+}<300, \mathrm{y}_{\mathrm{P}}^{+}=\rho \mathrm{c}_{\mu}^{1 / 4} \mathrm{k}_{\mathrm{P}}^{1 / 2} \mathrm{y}_{\mathrm{P}} / \mu, \mathrm{u}_{*}=\mathrm{c}_{\mu}^{1 / 4} \mathrm{k}_{\mathrm{P}}^{1 / 2}$,

which can be obtained with the assumption of local equilibrium of turbulence (see Rodi [9]). In the zero-equation turbulence models, theturbulence energy $\mathrm{k}$ is not solved, hence ${ }^{\lambda}$ is determined by

$$
\lambda=\rho u_{*} \kappa / \ln \left(E y_{P}^{+}\right), y_{P}^{+}=\rho u_{*} y_{P} / \mu,
$$

In three $k-\varepsilon "$ turbulence models, the turbulence generation $\mathrm{Ph}$ and thedissipation rate near the wall are determined by,

$$
\mathrm{P}_{\mathrm{h}, \mathrm{p}}=\tau_{\mathrm{w}}^{2} / \kappa \mu \mathrm{y}_{\mathrm{P}}^{+}, \varepsilon \mathrm{p}=\mathrm{c}_{\mu}^{3 / 4} \mathrm{k}_{\mathrm{p}}^{3 / 2} / \kappa \mathrm{y}_{\mathrm{P}}
$$

\section{Analytical Solutions}

\subsection{Gradually Expanded Channel Flow with Their Hydrodynamic Characteristics}

In Luo[10], the proposed resultant equations are :

1. For $0^{\circ}<\beta<4.6^{\circ}, \mathrm{p} *=1.105 \beta-0.565 \beta^{2}+0.08 \beta^{3} \leqq 0.5$

A. Primary velocity profile

$$
\frac{\mathrm{U}(\mathrm{y})}{\mathrm{u}_{*}}=\frac{1}{\kappa} \ln \left(\frac{10 \mathrm{yu}_{*}}{\nu}\right)+\frac{\mathrm{K}}{2 \kappa}\left(\frac{\mathrm{yp}^{*}}{\mathrm{r}}\right)\left(\frac{\mathrm{U}_{0}}{\mathrm{u}_{*}}\right)^{2}
$$

B. Turbulent shear stress profile

$$
\frac{\tau_{\mathrm{w}}}{\rho}=\mathrm{u}_{*}^{2}+\frac{\mathrm{p}^{*} \mathrm{U}_{0}^{2} \mathrm{y}}{4 \mathrm{r}}
$$

C. Turbulent viscosity coefficient

$$
\nu_{(\mathrm{ty})}=\frac{\left(\tau_{\mathrm{w}} / \rho\right)}{[\mathrm{dU}(\mathrm{y}) / \mathrm{dy}]}=\kappa \mathrm{yu}_{*}
$$

D. Turbulent kinetic energy profile

$$
\overline{\mathrm{k}}=\frac{1}{2}\left\{\begin{array}{c}
0.027\left(\frac{v \mathrm{~B}_{0} \overline{\mathrm{U}}+v \mathrm{~h}_{0} \mathrm{U}_{0}}{\mathrm{U}_{0} \mathrm{~h}_{0} \mathrm{~B}_{\mathrm{e}} \overline{\mathrm{U}}}\right)^{1 / 4} \mathrm{U}^{2} \\
+\left(\frac{3 \mathrm{p}^{*} \mathrm{U}_{0}^{2} \mathrm{y}}{10 \mathrm{r} \cos \beta}\right)+ \\
-\frac{\mathrm{U}_{0}^{4} \mathrm{y}^{4} \mathrm{p}^{* 2} \sec ^{2} \beta}{30 \mathrm{r}^{4} \mathrm{u}_{*}^{2}}
\end{array}\right\}
$$

E. Energy dissipation rate profile

$$
\bar{\varepsilon}=\mathrm{c}_{\mu} \frac{\overline{\mathrm{k}}^{2}}{\overline{\mathrm{v}}_{\mathrm{t}}}
$$




\section{F. Dispersion Coefficient}

$$
\begin{gathered}
\overline{\mathrm{D}}_{\mathrm{y}}=\frac{-1}{\mathrm{~B}_{\mathrm{e}}} \int_{0}^{\mathrm{B} \mathrm{e}} \mathrm{U}^{\prime}(\mathrm{y}) \int_{0}^{\mathrm{y}} \frac{1}{v_{\mathrm{ty}}} \int_{0}^{\mathrm{y}} \mathrm{U}^{\prime}(\mathrm{y}) \text { dydydy } \\
\text { and } \quad \mathrm{U}(\mathrm{y})-\overline{\mathrm{U}}(\mathrm{y})=\mathrm{U}^{\prime}(\mathrm{y})
\end{gathered}
$$

where $\bar{U}(y)$ is the integration of $U(y)$ with respect to the width $\mathrm{B}$ along the flow

$$
\overline{\mathrm{D}}_{\mathrm{y}}=\frac{\mathrm{u}_{*} \mathrm{~B}_{\mathrm{e}}}{2 \mathrm{\kappa}^{3}}+\frac{0.625 \mathrm{p}^{*} \mathrm{~B}_{\mathrm{e}}^{2} \mathrm{U}_{0}^{2}}{12 \kappa^{2} \mathrm{ru}_{*}}-\frac{\mathrm{p}^{* 2} \mathrm{~B}_{\mathrm{e}}^{3} \mathrm{U}_{0}^{4}}{123 \mathrm{r}^{2} \mathrm{u}_{*}^{3} \kappa}
$$

2. $\quad$ For $\beta \geqq 4.6^{\circ}$ and $p *=0.5$ for $\beta \geqq 4.6^{\circ}$ :

A. Primary velocity profile

$$
\frac{\mathrm{U}(\mathrm{y})}{\mathrm{u}_{*}}=\frac{2}{\kappa}\left(\frac{\mathrm{y}}{\iota}\right)^{1 / 2}=\frac{2}{\kappa}\left(\frac{\mathrm{yp}^{*}}{\mathrm{r}}\right)^{1 / 2}\left(\frac{\mathrm{U}_{0}}{\mathrm{u}_{*}}\right)\left(\frac{\mathrm{B}_{0}}{\mathrm{~B}_{\mathrm{e}}}\right)
$$

B. Turbulent shear stress profile

$$
\frac{\tau_{\mathrm{w}}}{\rho}=\left(\frac{\mathrm{U}_{0} \mathrm{u}_{*} \mathrm{~B}_{0}}{\mathrm{~B}_{\mathrm{e}}}\right)\left(\frac{\mathrm{y}}{2 \mathrm{r}}\right)^{1 / 2}
$$

C. Turbulent viscosity coefficient

$$
v_{(\mathrm{ty})}=\frac{\left(\tau_{\mathrm{w}} / \rho\right)}{[\mathrm{dU}(\mathrm{y}) / \mathrm{dy}]}=\kappa y u_{*}
$$

D. Turbulent kinetic energy profile

$$
\begin{array}{r}
\overline{\mathrm{k}}=\frac{1}{2}\left(\overline{\mathrm{u}^{/ 2}}+\overline{\mathrm{v}^{/ 2}}\right)=\frac{1}{2 \rho}\left(\bar{\tau}_{\mathrm{xx}}+\bar{\tau}_{\mathrm{yy}}\right) \\
=\frac{1}{2}\left\{\begin{array}{c}
0.027\left(\frac{v \mathrm{~B}_{\mathrm{e}} \overline{\mathrm{U}}+v \mathrm{~h}_{0} \mathrm{U}_{0}}{\mathrm{U}_{0} \mathrm{~h}_{0} \overline{\mathrm{U}} \mathrm{B}_{\mathrm{e}}}\right)^{1 / 4} \mathrm{U}^{2} \\
+\left(\frac{13 \mathrm{U}_{0} \mathrm{u}_{*} \mathrm{y}}{20 \mathrm{r} \cos \beta}\right)\left(\frac{\mathrm{B}_{\mathrm{e}}}{\mathrm{B}_{0}}\right)^{1 / 4}+ \\
-\frac{\mathrm{U}_{0}^{2} \mathrm{y}^{2} \mathrm{~B}_{0}^{2}}{36 \mathrm{k}^{2} \mathrm{r}^{2} \mathrm{~B}_{\mathrm{e}}^{2}}
\end{array}\right\}
\end{array}
$$

E. Energy dissipation rate profile

$$
\bar{\varepsilon}=c_{\mu} \frac{\bar{k}^{2}}{\bar{v}_{\mathrm{t}}}
$$

F. Dispersion Coefficient

$$
\overline{\mathrm{D}}_{\mathrm{y}}=\left(\frac{16 \mathrm{~B}_{\mathrm{e}}^{2}}{\kappa^{3} \mathrm{r}}\right)\left(\frac{\mathrm{U}_{0}^{2}}{\mathrm{u}_{*}}\right)\left(\frac{\mathrm{B}_{0}}{\mathrm{~B}_{\mathrm{e}}}\right)^{2}
$$

3. For $\beta=0^{\circ}$ :

A. Primary velocity profile

$$
\frac{\mathrm{U}(\mathrm{y})}{\mathrm{u}_{*}}=\frac{1}{\kappa} \ln \left(\frac{10 \mathrm{yu}_{*}}{\nu}\right)
$$

B. Turbulent shear stress profile

$$
\frac{\tau_{\mathrm{w}}}{\rho}=\mathrm{u}_{*}^{2}
$$

C. Turbulent viscosity coefficient

$$
v_{(\mathrm{ty})}=\frac{\left(\tau_{\mathrm{w}} / \rho\right)}{[\mathrm{dU}(\mathrm{y}) / \mathrm{dy}]}=\kappa \mathrm{yu} \mathrm{u}_{*}
$$

\section{Turbulent kinetic energy profile}

$$
\overline{\mathrm{k}} \fallingdotseq \frac{1}{2}\left\{0.027\left(\frac{v \mathrm{~B}_{0} \overline{\mathrm{U}}+v \mathrm{~h}_{0} \mathrm{U}_{0}}{\mathrm{U}_{0} \mathrm{~h}_{0} \overline{\mathrm{U}} \mathrm{B}_{0}}\right)^{1 / 4} \cdot \mathrm{U}^{2}\right\}
$$

E. Energy dissipation rate profile

$$
\bar{\varepsilon}=c_{\mu} \frac{\overline{\mathrm{k}}^{2}}{\bar{v}_{\mathrm{t}}}
$$

F. Dispersion Coefficient

$$
\overline{\mathrm{D}}_{\mathrm{y}}=\frac{0.404}{\mathrm{\kappa}^{3}} \mathrm{~B}_{\mathrm{e}} \mathrm{u}_{*}
$$

\subsection{Abruptly Expanded Channel Flow with Their Hydrodynamic Characteristics (For $\left.\beta=90^{\circ}\right)$}

In view of the Newtonian principle of motion between action and reaction, moreover, it is realized that deceleration of the fluid in the jet can occur only through simultaneously acceleration of the surrounding fluid, so that the total rate of flow passion through successive sections of the jet actually increases with distance from the outlet. In this case, $\beta=90^{\circ}$, the circulating flow situation happens from the entrance until certain distance downstream. Within the circulation region, convective term, diffusion term, bottom stress, and the dispersion term in 2-D modeling exist due to the reason for the depth-integrated method from 3-D flow equation. The new velocity profile must be re-derived. See Albertson [11] and the analytical results are solved here.

\subsubsection{Primary Velocity Profile}

The approximate characteristics of the corresponding mean flow pattern are expressed based on the assumptions that; (1) the pressure is hydrostatically distributed through the flow; (2) the diffusion process is dynamically similar under all conditions; (3) the longitudinal component of velocity within the diffusion region varies according to the normal probability function at each cross section

$$
\frac{\mathrm{U}}{\mathrm{U}_{\max }}=\operatorname{Exp}\left[-\frac{\mathrm{y}^{2}}{2 \sigma^{2}}\right]
$$

in which $\mathrm{y}$ is the lateral distance counted from the centerline of the expanding channel, while $\sigma$ is the lateral distance where $\mathrm{U}=0.605 \mathrm{Umax}$. Based on the condition of dynamic similarity simultaneously $\sigma / \mathrm{x}=$ constant $=\mathrm{C}$ is required that at all cross-section, regardless of the efflux velocity. It hints the angle of jet diffusion must be constant.

By using the mixing-length-hypothesis,

$$
\ell_{\mathrm{n}}\left(\frac{\mathrm{U}}{\mathrm{U}_{0}}\right)=-42.3\left(0.096+\frac{\mathrm{y}-\frac{\mathrm{b}_{0}}{2}}{\mathrm{x}}\right)^{2}
$$

and

$$
\ell_{\mathrm{n}}\left(\frac{\mathrm{U}}{\mathrm{U}_{0}}\right)\left[\sqrt{\frac{\mathrm{x}}{\mathrm{b}_{0}}}\right]=0.83-4.24\left(\frac{\mathrm{y}^{2}}{\mathrm{x}^{2}}\right)
$$

where Eq.(41) is for the zone of flow establishment, 
$\mathrm{x} \leqq \mathrm{x} 0$, and Eq. (42) is for the zone of established flow, $\mathrm{x} \geqq$ $\mathrm{x} 0$, and

$$
\mathrm{x}_{0}=5.2 \mathrm{~b}_{0}
$$

The limitation of the lateral velocity $\mathrm{V}$, based on the momentum conservation and mixing length-hypothesis, is

$$
\begin{gathered}
\lim _{n \rightarrow \infty}\left(\frac{v}{U_{0}}\right) \sqrt{\frac{x}{b_{0}}}=-0.155 \\
\frac{\partial u}{\partial x}+\frac{\partial v}{\partial y}=0
\end{gathered}
$$

\subsubsection{Turbulent Shear Stress}

$$
\begin{gathered}
\mathrm{T}_{\mathrm{xx}}^{*}=0.04 \mathrm{q}_{v}^{2} \mathrm{H}+0.02 \mathrm{q}_{v}^{2} \mathrm{H} \\
\mathrm{T}_{\mathrm{yy}}^{*}=0.04 \mathrm{q}_{v}^{2} \mathrm{H}+7.2 \mathrm{q}_{v}^{2}\left(\frac{\mathrm{H}^{2}}{\mathrm{r}_{\mathrm{c}}}\right) \\
\mathrm{T}_{\mathrm{xy}}^{*}=0.015 \mathrm{q}_{v}^{2} \mathrm{H}+0.34 \mathrm{q}_{v}^{2}\left(\frac{\mathrm{H}^{2}}{\mathrm{r}_{\mathrm{c}}}\right) \\
\overline{\mathrm{u}^{\prime} v^{\prime}}=0.015 \mathrm{q}_{v}^{2}=-v_{1} \frac{\partial \mathrm{U}}{\partial \mathrm{y}} ; \mathrm{q}_{v}=\sqrt{\mathrm{U}^{2}+\mathrm{V}^{2}}
\end{gathered}
$$

\subsubsection{Turbulent Viscosity Coefficient}

$$
v_{\mathrm{ty}}=-\frac{\overline{\mathrm{u}^{\prime} v^{\prime}}}{(\partial \mathrm{U} / \partial \mathrm{y})}=\frac{\mathrm{q}_{\mathrm{v}} \mathrm{x}^{2}}{565 \mathrm{y}} ; v_{\mathrm{ty}=0}=v_{\mathrm{ty}=\frac{\mathrm{b}_{0}}{2}} ;
$$

\subsubsection{Turbulent Kinetic Energy Profile}

$$
\begin{gathered}
\overline{\mathrm{k}}=0.015 \mathrm{q}_{v}^{2}+1.85 \mathrm{q}_{v}^{2}\left(\frac{\mathrm{H}}{\mathrm{r}_{\mathrm{c}}}\right) \\
\mathrm{x}_{\mathrm{e}}=(40 \mathrm{or} 5)\left(\frac{\mathrm{b}}{2}-\frac{\mathrm{b}_{0}}{2}\right) \\
\mathrm{r}_{\mathrm{c}}=\frac{1}{2}\left(\sqrt{\mathrm{H}_{\mathrm{c}}^{2}+\mathrm{x}_{\mathrm{E}}^{2}}\right) \csc \alpha=\frac{1}{2}\left(\sqrt{17\left(\frac{\mathrm{b}}{2}-\frac{\mathrm{b}_{\mathrm{o}}}{2}\right)^{2}}\right)(\sqrt{17})=8.5\left(\frac{\mathrm{b}}{2}-\frac{\mathrm{b}_{0}}{2}\right) \\
\mathrm{c}_{\mathrm{k}}=\frac{1}{\sqrt{\mathrm{c}_{\mathrm{f}}}} ; \mathrm{c}_{\varepsilon}=\frac{3.6 \mathrm{c}_{2 \varepsilon}}{\mathrm{c}_{\mathrm{f}}^{3 / 2}} \sqrt{\mathrm{c}_{\mathrm{u}}} \\
\mathrm{c}_{1 \epsilon}=\mathrm{c}_{2 \epsilon}-\frac{\mathrm{k}^{2}}{\sigma \sqrt{\mathrm{c}_{\mu}}} \\
\mathrm{c}_{\mu}=0.09 ; \mathrm{c}_{1 \varepsilon}=1.44 ; \mathrm{c}_{2 \varepsilon}=1.92 ; \sigma_{\mathrm{k}}=1.0 ; \sigma_{\varepsilon}=1.3
\end{gathered}
$$

\subsubsection{Energy Dissipation Rate Profile}

$$
\bar{\varepsilon}=\mathrm{c}_{\mu} \frac{\overline{\mathrm{k}^{2}}}{\overline{v_{\mathrm{t}}}}
$$

\subsubsection{Coefficient of Energy Loss}

Problems of major concern related to the efficiency and safety of sudden enlargement energy dissipation are the loss coefficient, cavitation potential and pressure fluctuation for a certain type of in-line sudden enlargement dissipator, even for a series of sudden enlargement which has been researched by Zhang [12].

It is well-known that the loss in head at the sudden enlargement can be approximately expressed by the Borda formula:

$$
\Delta \mathrm{H}=\frac{\left(\mathrm{U}_{0}-\mathrm{U}\right)^{2}}{2 \mathrm{~g}}=\left(1-\frac{\mathrm{A}_{0}}{\mathrm{~A}}\right)^{2} \frac{\mathrm{U}_{0}^{2}}{2 \mathrm{~g}}=\mathrm{k}_{\mathrm{L}}\left(\frac{\mathrm{U}_{0}^{2}}{2 \mathrm{~g}}\right)
$$

It is clear to see that the efficiency of energy dissipator through sudden enlargement depends very much on the loss coefficient of the relevant enlargement. The head losses are often measured at the reference points, such as four widths of downstream of the enlargement. And from the above equation and the measured points where the eddy action or turbulence approaches to minimum, velocity distribution across the cross-section of open channel becomes practically uniform and pressure head reaches a constant value, the Borda formula can then be used to determine its loss coefficient kL with sufficient accuracy and the safe side.

$$
\begin{gathered}
\mathrm{k}_{\mathrm{L}}=\frac{\mathrm{E}_{0}-\mathrm{E}}{\left(\frac{\mathrm{U}_{0}^{2}}{2 \mathrm{~g}}\right)}=\left(1-\frac{\mathrm{A}_{0}}{\mathrm{~A}}\right)^{2} \\
\mathrm{E}_{0}=\frac{\mathrm{U}_{0}^{2}}{2 \mathrm{~g}}+\mathrm{h}_{0} ; \mathrm{E}=\frac{\overline{\mathrm{U}^{2}}}{2 \mathrm{~g}}+\mathrm{h} \\
\mathrm{h}=\frac{\mathrm{U}_{0} \mathrm{~h}_{0}}{\overline{\mathrm{U}}} \\
\overline{\mathrm{U}}=\left(\frac{4 \mathrm{U}_{0}}{\mathrm{~b}}\right)\left(\sqrt{\mathrm{xb}_{0}}\right)\left[\operatorname{erf}\left(\frac{1.03 \mathrm{~b}_{0}}{\mathrm{x}}\right)-\frac{1}{2}\right]
\end{gathered}
$$

where $\mathrm{U} 0$ is the velocity of inflow and h0 is the depth of inlet, and $\mathrm{h}$ will be set as the same value of inlet for diverging wall flow, $0^{\circ}<\beta<4.6^{\circ}$, and the abruptly expanded channel flow. From the view point of the diffuser pressure recovery of gradually and abruptly expanded pipe flow, the upper limit of Reynolds number is 75,000. For the case of open channel flow, the maximum applied Reynolds number will be one-fourth of the magnitude of pipe flow because the characteristic length, the diameter of the pipe, is four times of the open channel hydraulic radius.

\section{Results, Comparisons and Discussion}

\subsection{Gradually Expanded Channel Flow}

The 2-DH gradually expanded flow numerical scheme with different angel of $\beta$, such as Yu et al [13] and Gayathri S. et al. [ 14], is in Fig.1, and the comparisons between numerical and analytical results are following in Figs. 2, 3, and 4, respectively.

\subsection{Abruptly Expanded Channel Flow}

The comparisons for the abruptly expanded channel flows, between the analytical results, by using Eqs.(41) and (42) for developing and developed regions of submerged jets, respectively, and the numerical results from Tran Thuc[15] are presented in Figs. 5 and 6 which express the velocity profile in the primary flow direction. The well agreements are obtained within the region of the developing submerged jets but the sharper shapes of normal distribution from numerical results are found in the developed zone. This is due to the end wall effect at the 
outlet. The suddenly reduce opening of the outlet will form three-dimensional flow situation and affect the turbulent phenomena and quantities in this developed regions, say $\mathrm{x} \geqq 5$.2b0,but the effect of end wall of outlet will not reach in the developing regions. Another numerical results of the abruptly varied channel without the end wall and with enough pool length are run. The good agreements are obtained in Fig. 6. The comparison of turbulent kinetic energy and energy dissipation rare between analytical and numerical results for the case of enough pool length without end wall effect are shown in Fig. 7 which is without considering the dispersion effects in the analytical solutions in Eq (51). The good trends and acceptable comparisons between analytical and numerical results presented. The $\mathrm{kL}$ is also compared for the abruptly expanded flow situations between approximate results in Eq. (58) and Borda and Zhang [12] in Fig. 10. The quite good agreement is obtained again.

\section{Conclusions and Application}

\subsection{Gradually Expanded Channel Flow}

1. The analytical primary velocity profiles, profiles of turbulent kinetic energy and energy dissipation rate for twodimensional horizontal plane diffuser-wall flows outside of the turbulent boundary layers are compared with the corresponding situations from the numerical results. It can be seen from Fig. 2 that the uniform velocity at inlet of $0.5 \mathrm{~m} / \mathrm{s}$ decreases as it moves downstream. These velocity profiles at $x=0.5,1.0,1.5$, and $2.0 \mathrm{~m}$ are in Fig. 3 together with $\mathrm{k}$ and $\varepsilon$, which shows that $\mathrm{k}$ and edecrease as $\mathrm{x}$ increase but at slower rate than $\mathrm{U}$. The turbulent kinetic energy shows the smallest reduction from upstream to downstream. These are due to the jet flux and the increasing of turbulent boundary thickness along the flow, respectively. The more uniform decreasing on velocity along the flow to the downstream for a given divergent channel makes the flow better stable even with a little bit decreasing with $\mathrm{k}$ and $\varepsilon$, this regulation will give good flow control before the flow goes into power plant in order to avoid the damage on the instruments.

2. The comparisons of analytical and numerical results about velocity, turbulent kinetic energy and energy dissipation rate for different $\beta$-value at the position of $x$ $=2.0 \mathrm{~m}$ from the inlet are shown in Fig. 4 . From this figure in the case of $\beta=3^{\circ}$, the differences between analytical and numerical results on the velocity profile and two turbulent items are very limited. When $\beta=6^{\circ}$, which is located in the region of transition zone of diffuser-wall flows from small core-angel to big one, the comparisons of primary velocity profile, turbulent kinetic energy and energy dissipation rate between analytical and numerical results give a little smaller values than the ones for $\beta=3^{\circ}$, but the trends and the agreements are still agreeable and acceptable.
3 . In the case of big core-angel diffuser-wall flow, such as $\beta=30^{\circ}$ or $\beta=60^{\circ}$, which show higher values of $\mathrm{k}$ and ethan the results of $\beta=3^{\circ}$ and $\beta=6^{\circ}$ shown. From Fig. 3, the analytical results of primary velocity and the two turbulent items are larger than the numerical ones at the positions near the inlet, such as $\mathrm{x}=0.5 \mathrm{~m}$. This is due to the different distribution forms of primary velocity, the parabolic distribution for analytical result while logarithmic formula for the numerical one. The logarithmic distribution has higher turbulence and energy loss near to the wall, therefore, the higher turbulent kinetic energy and energy dissipation rate with larger primary velocity are presented near wall, too. And the parabolic form for analytical solutions just express the inverse phenomena.

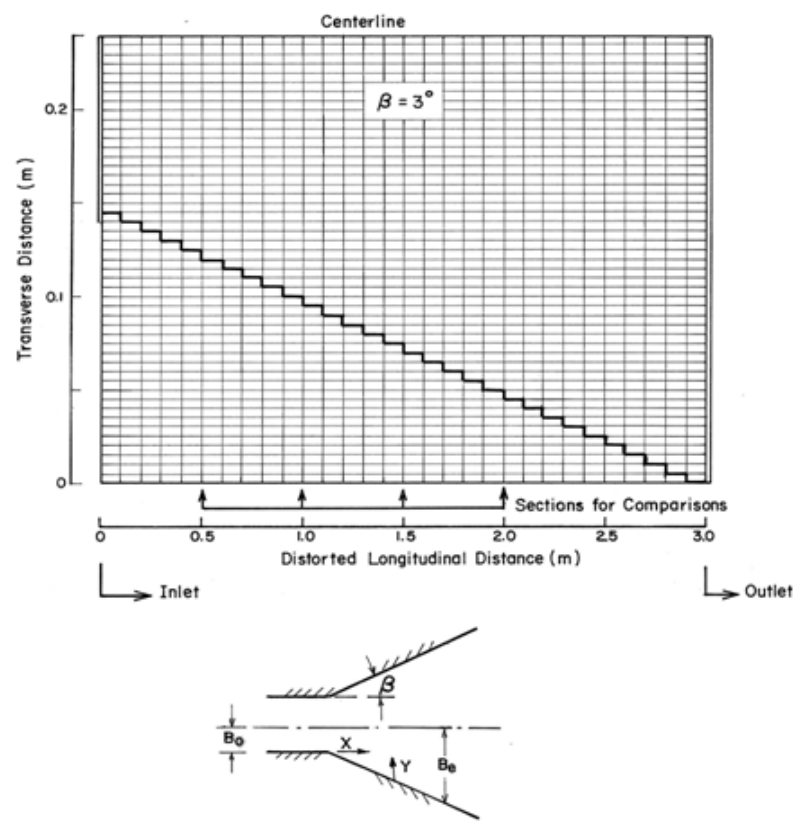

Fig 1. Grid system used in two dimensional depth-averaged model of $\beta=$ $3^{\circ}$ with $L=3 m, \Delta x=0.1 \mathrm{~m}, \Delta y=0.01 \mathrm{~m}, \Delta t=0.06 \mathrm{sec}$.

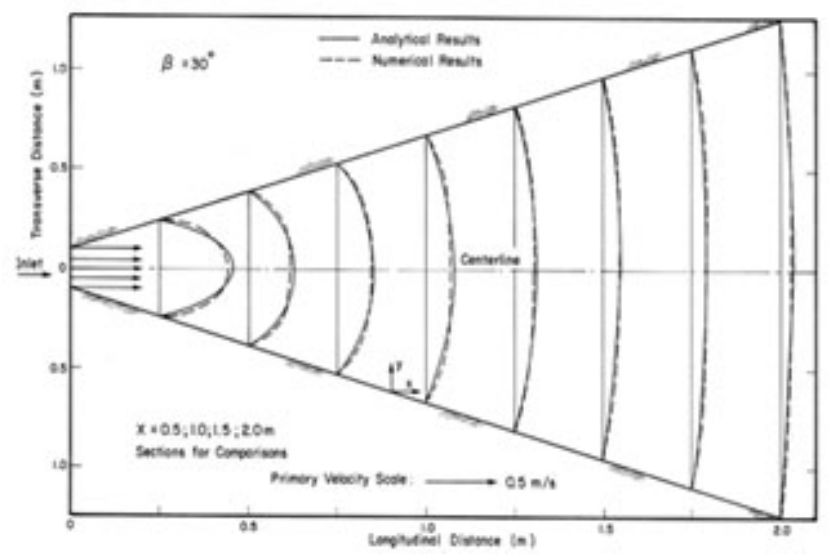

Fig 2. Comparisons of analytical and numerical primary velocity profiles for $\beta=30^{\circ}, U O=0.5 \mathrm{~m} / \mathrm{s}, h 0=0.15 \mathrm{~m}$, and $B 0=0.10 \mathrm{~m}$. 

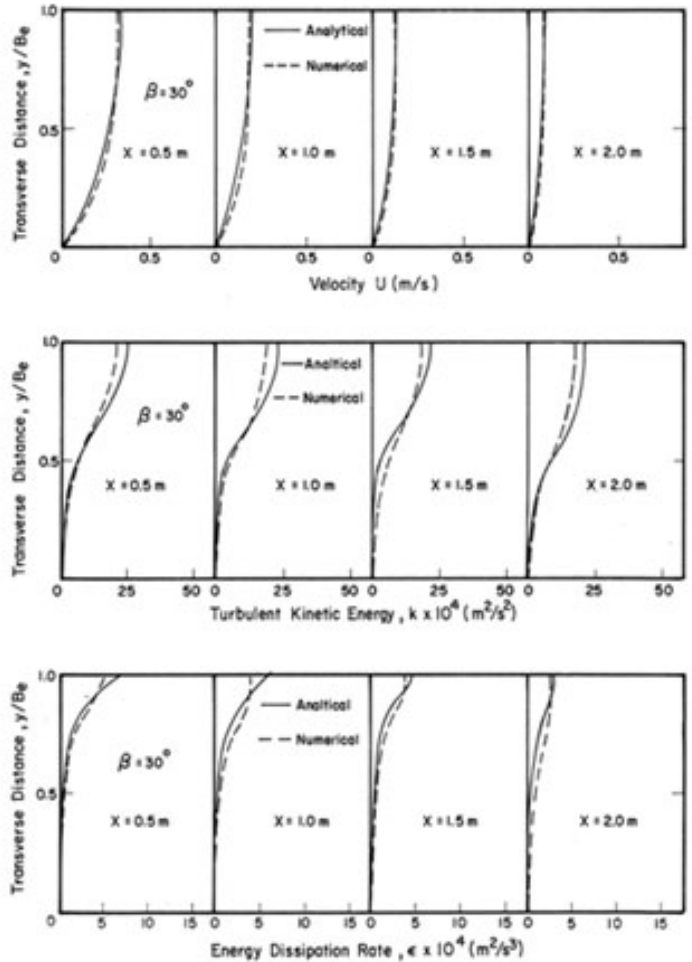

Fig 3. Comparisons of primary velocity $U$, turbulent kinetic energy $k$, and energy dissipation rate $\varepsilon$, between analytical and numerical results for diffuser-wall flow with $\beta=30^{\circ}, v=0.001 \mathrm{~m} 2 / \mathrm{s}, U 0=0.5 \mathrm{~m} / \mathrm{s}, h 0=0.15 \mathrm{~m}$, and $B O=0.10$ m.along the primary flow direction

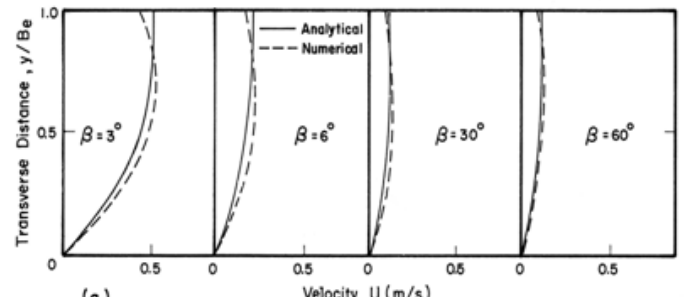

(a)

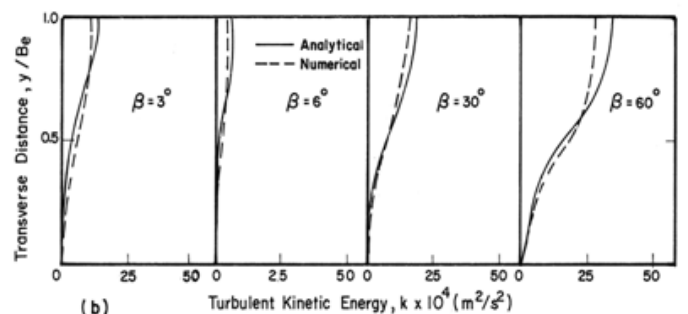

(b)

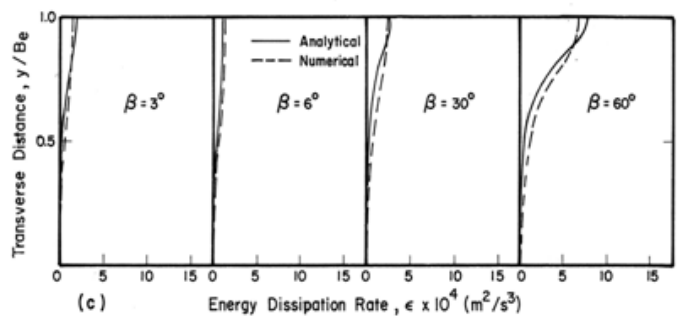

Fig 4. Comparisons of primary velocity $U$, turbulent kinetic energy $k$, and energy dissipation rate $\varepsilon$, between analytical and numerical results for different diffuser-wall $\beta$-value flow with $v=0.001 \mathrm{~m} 2 / \mathrm{s}, U 0=0.5 \mathrm{~m} / \mathrm{s}, \mathrm{h} 0$ $=0.15 \mathrm{~m}, \quad B 0=0.10 \mathrm{~m}$, and $X=2 \mathrm{~m}$. along the primary flow direction
4. When $\beta<0^{\circ}$, the dispersion coefficient can be expressed as the following equation, Eq.(62), and after the comparisons of the magnitude of turbulent viscosity and dispersion coefficients with different $\beta$-value for different relative width, the results are obtained as Eqs. (63) and (64), then the relative scales of mean dispersions coefficients are presented in Fig. 8.

$$
\begin{aligned}
& \bar{D}_{y}=-\frac{1}{B_{e}} \int_{0}^{B_{e}} D_{y} d y \text {, that is, } \\
& \overline{\mathrm{D}}_{\mathrm{y}}=\left(\frac{\beta^{2} \mathrm{u}_{*} \mathrm{~B}_{\mathrm{e}}}{2 \kappa^{3}}\right)\left[\frac{\left(\frac{1 \mathrm{U}_{\mathrm{c}}}{\kappa \mathrm{u}_{*}}-5.208\right)^{2}}{\left(27.12+\frac{\beta^{2}}{\kappa^{4}}\right)}\right]-\left(\frac{\beta^{3} \mathrm{u}_{*} \mathrm{~B}_{\mathrm{e}}}{8 \kappa^{3}}\right)\left[\frac{\left(\frac{1 \mathrm{U}_{\mathrm{c}}}{\kappa \mathrm{u}_{*}}-5.208\right)^{3}}{27.12+\frac{\beta^{2}}{\kappa^{4}}}\right]+ \\
& \left(\frac{\beta \mathrm{u}_{*} \mathrm{~B}_{\mathrm{e}}}{\kappa^{3}}\right)\left(\ln \mathrm{B}_{\mathrm{e}}\right)^{2}\left[\frac{\left(\frac{1 \mathrm{U}_{\mathrm{c}}}{\kappa \mathrm{u}_{*}}-5.208\right)^{2}}{\left(27.12+\frac{\beta^{2}}{\kappa^{4}}\right)}\right]+\left(\frac{\beta \mathrm{u}_{*} \mathrm{~B}_{\mathrm{e}}}{\kappa^{3}}\right)\left[\frac{\left(\frac{1 \mathrm{U}_{\mathrm{c}}}{\kappa \mathrm{u}_{*}}-5.208\right)^{2}}{\left(27.12+\frac{\beta^{2}}{\kappa^{4}}\right)}\right]\left(\ln \mathrm{B}_{\mathrm{e}}\right)- \\
& \left(\frac{2 \beta^{2} u_{*} B_{e}}{\kappa^{3}}\right)\left(1-\frac{1}{2} \ln B_{e}\right)\left[\frac{\left(\frac{1 U_{c}}{\kappa u_{*}}-5.208\right)^{2}}{\left(27.12+\frac{\beta^{2}}{\kappa^{4}}\right)}\right] \\
& \bar{v}_{\mathrm{t}, \beta<0,} \leq \bar{v}_{\mathrm{t}, \beta=0,} \leq \bar{v}_{\mathrm{t}, 0<\beta<4.6^{0}} \leq \bar{v}_{\mathrm{t}, \beta \geq 4.6^{0}} \text {, } \\
& \overline{\mathrm{D}}_{\beta<0,} \leq \overline{\mathrm{D}}_{\beta=0,} \leq \overline{\mathrm{D}}_{0<\beta<4.6^{0}} \leq \overline{\mathrm{D}}_{\beta \geq 4.6^{0}}
\end{aligned}
$$

5. With the following expressing equations for energy loss coefficient, $\mathrm{kL}$, on the situation of gradually expanded flow in Eqs. (58), (59), (60) and (61), and the analytical result of $\mathrm{kL}$ is compared with the result from Gerhart, et al [16] in Fig. 9. Good trends are obtained.

6 . From the trends of turbulent kinetic energy and energy dissipation rate of Fig. 4, it is found that these two turbulent items will increase significantly with increasing the half-angel, $\beta$. These are because of the phenomena of the jet flux, which reduces the primary velocity and increases the velocity fluctuation at the same time, and the increasing of turbulent boundary layer thickness, which has much more strong eddies with larger energy loss. Generally speaking, the analytical results based on the plane turbulent free jets for diffuser-wall flows can be valid for wide range of $\beta$-value, such as from $\beta=3^{\circ}$ to $\beta=60^{\circ}$. The transfer due to diffusion or dispersion phenomena from Yang C. S. et al [17] can be study and discuss further and compare with the diffusion or dispersion coefficients for different divergent angels of this research. Here, in Fig.9, of $2 \beta=180^{\circ}$, the $\mathrm{kL}$ is between 1.0 and 1.1 , and this result has good match one with that of abruptly expanded flow situations on radius or width ratio equal to zero, which means $\beta=90^{\circ}$, in Fig. 10 .

7. The energy dissipation rate, $\varepsilon$, in Fig. 4, has the consistency with the trend of Fig. 9, on energy loss coefficient, and this shows us again that flow regulation with divergent channel can effectively reach flow uniformity with reduction of the turbulence in main flow direction for mitigation on the damage risk of power plant. We also can get some good information from Eqs. (63) and (64), for both turbulent viscosity for sedimentation and dispersion coefficient for contamination. These parameters express the significant efficiencies on solid particles spreading or settlement on the width direction to protect the 
turbines.

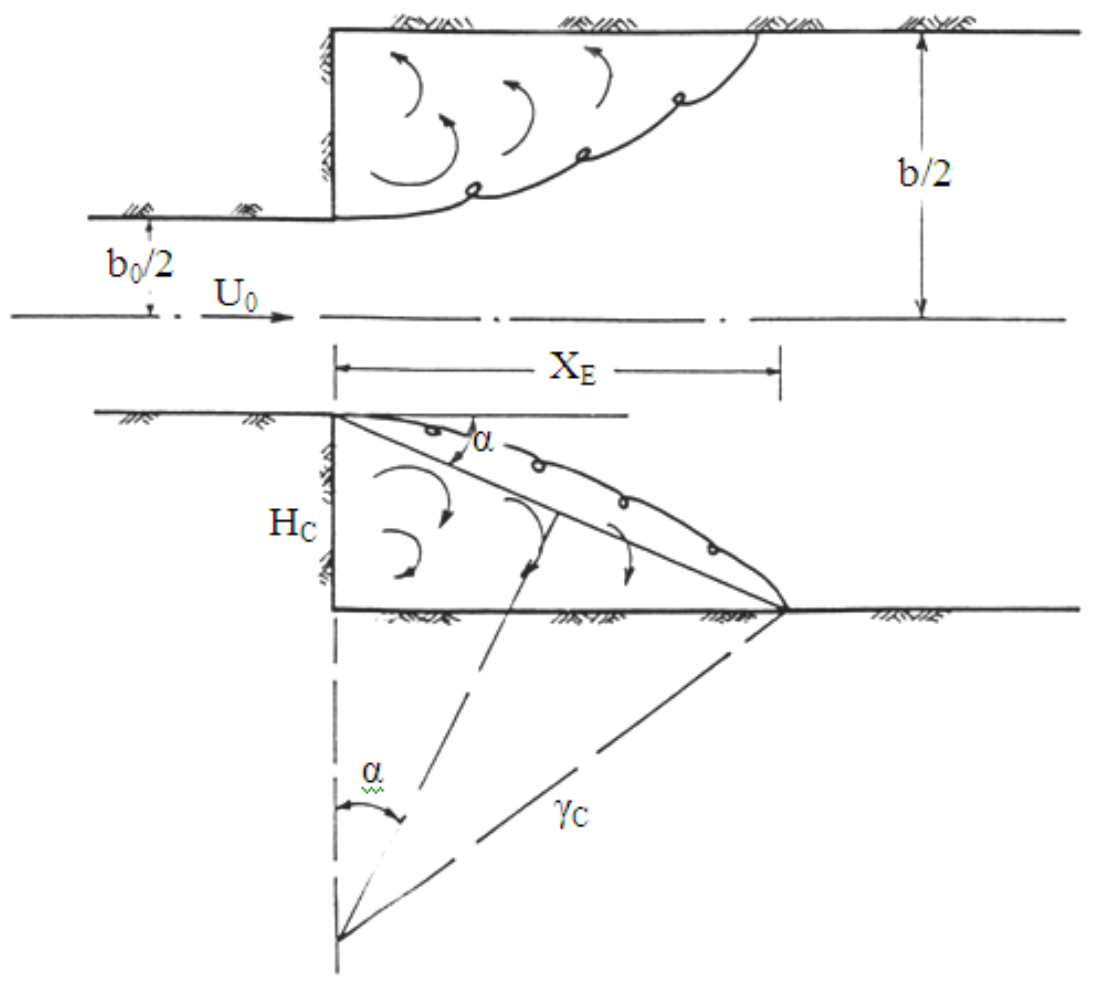

Fig 5. The Definition of Abruptly Expanded Flow

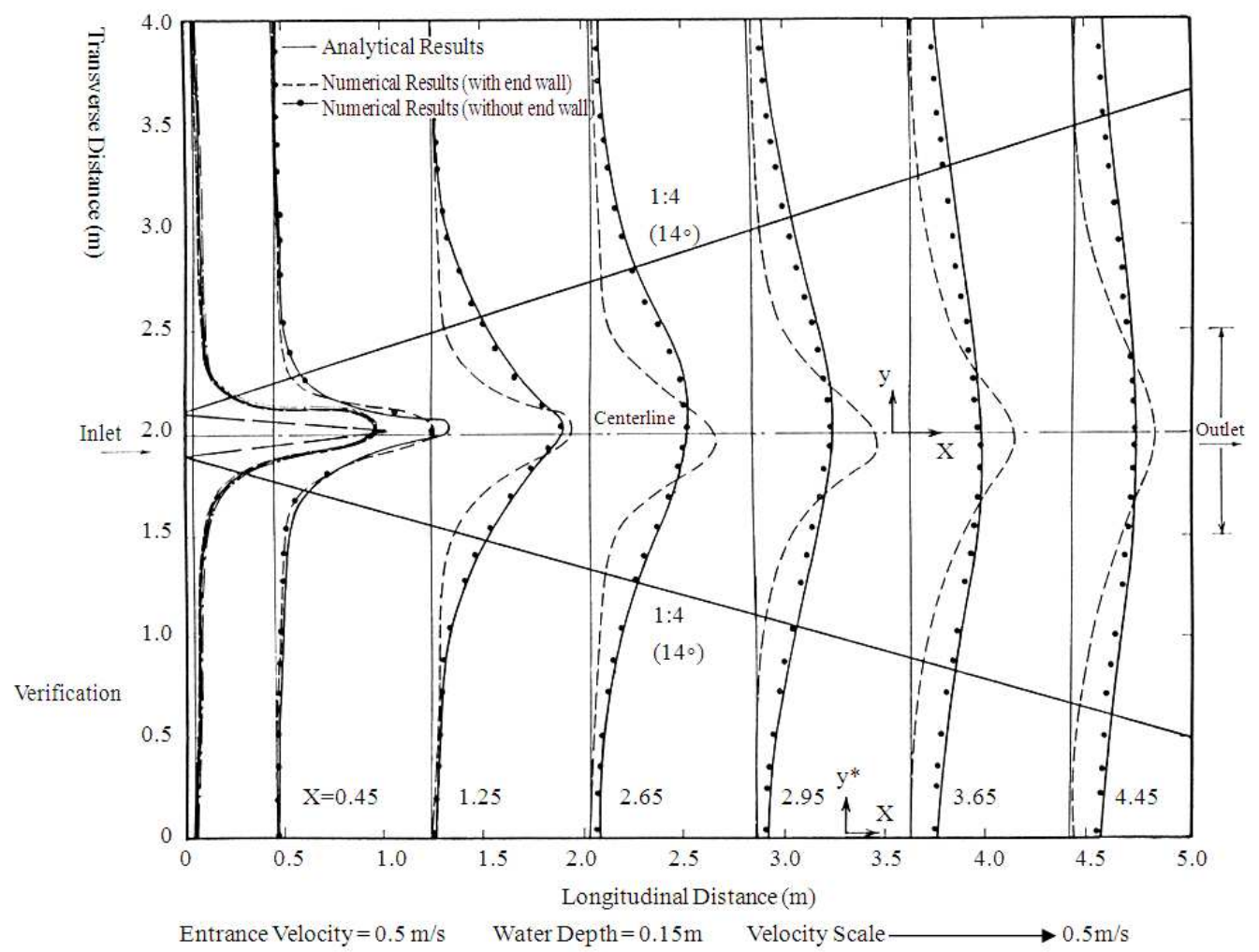

Fig 6. Comparison of Analytical and Numerical X - component Velocity Depth - AveragedHydrodynamic Model for Abruptly Varied Flows with $B 0=0.10 \mathrm{~m}, B=2.0 \mathrm{~m}, \beta=90 \square$ 


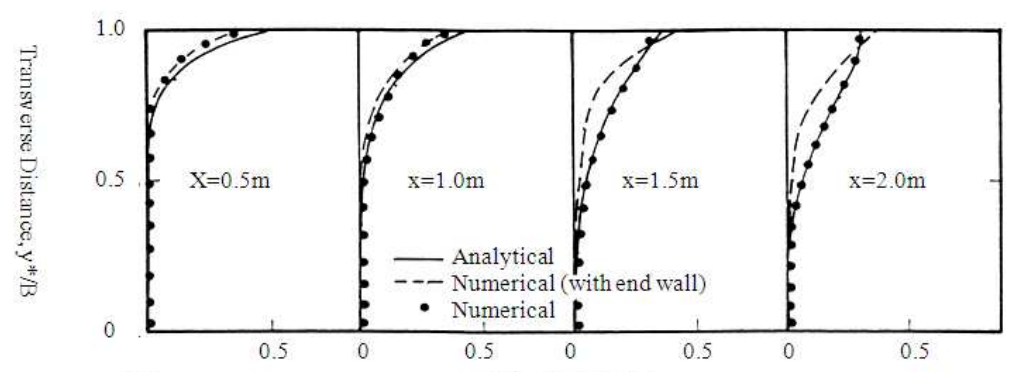

(a) Velocity, $\mathrm{U}(\mathrm{m} / \mathrm{s})$

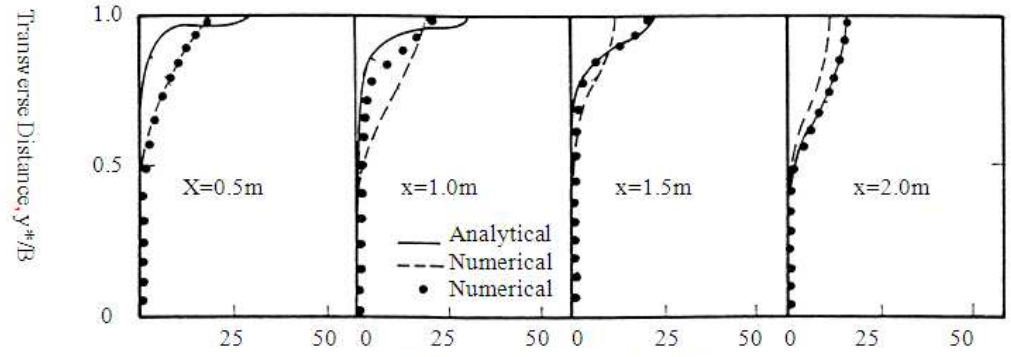

(b)

Turbulent Kinetic Energy, $\mathrm{kx} 10^{4}\left(\mathrm{~m}^{2} / \mathrm{s}^{2}\right)$

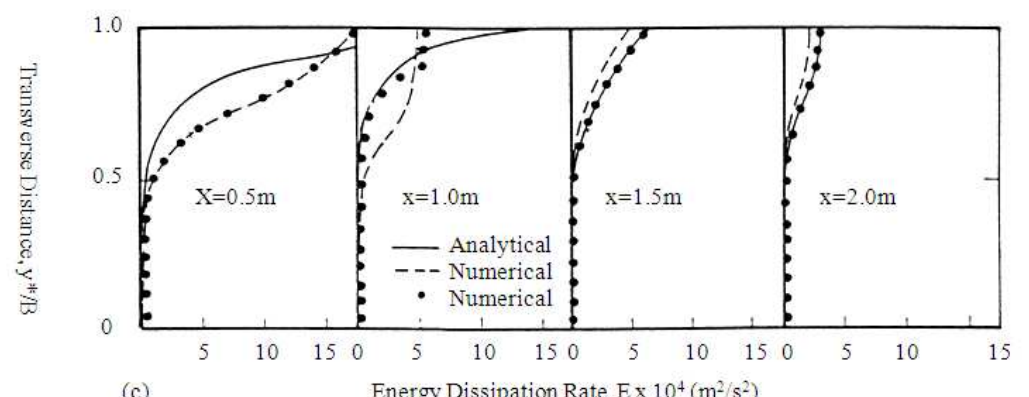

(c) Energy Dissipation Rate, $\mathrm{E} \times 10^{4}\left(\mathrm{~m}^{2} / \mathrm{s}^{2}\right)$

Fig 7. Comparisons of Primary Velocity, $U$, Turbulent Kinetic Energy, $k$, and Energy Dissipation Rate, E, between Analytical and Numerical Results on Abruptly Expanded Channel Flow with $\beta=90 \square, B 0=0.1 \mathrm{~m}, B=2.0 \mathrm{~m}$, Uin $=0.5 \mathrm{~m} / \mathrm{s}, H=0.15 \mathrm{~m}, v=1.01 \mathrm{~mm} 2 / \mathrm{s}$ for Different Position along the Flow without Considering Dispersion Effects

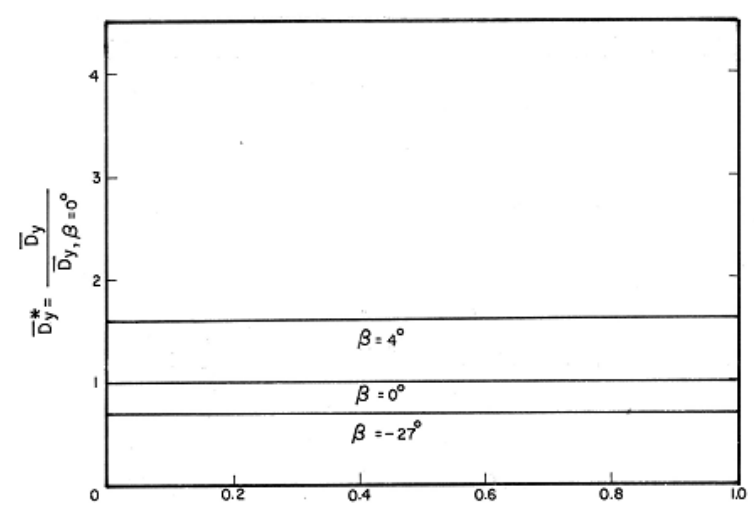

Fig 8. Distributions of dimensionless dispersion coefficients value outside boundary for different $\beta$-value with $B 0=5 \mathrm{~m}, X=10 \mathrm{~m}, U 0=0.7 \mathrm{~m} / \mathrm{s}$, friction velocity $0.050 \mathrm{~m} / \mathrm{s}, \kappa=0.4$, and $h=0.15 \mathrm{~m}$

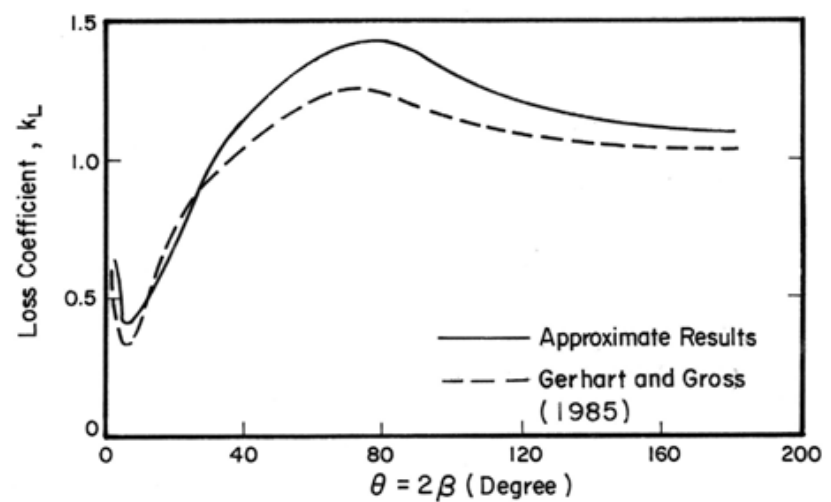

Fig 9. Comparison of energy loss coefficient, KL, for gradually divergent wall flow between approximate results and experimental ones from Gerhart, et al (1985) 


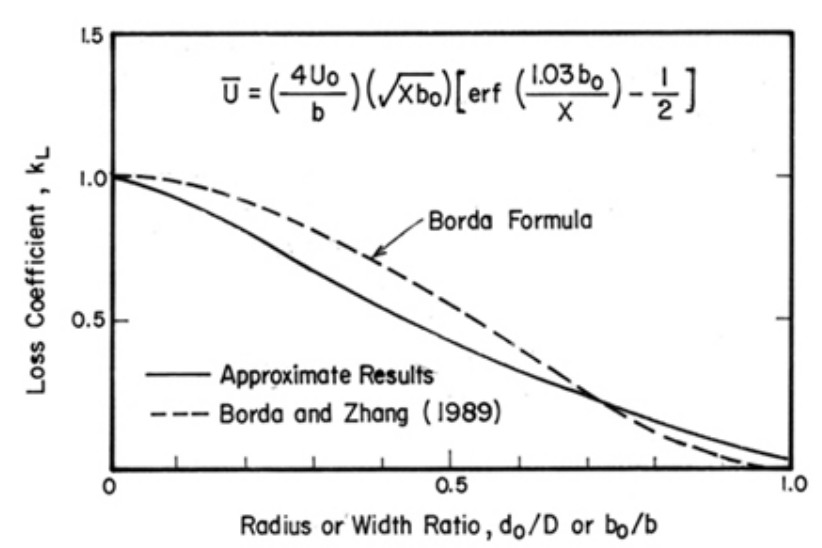

Fig 10. Comparison of energy loss coefficient, KL, for Abruptlyexpandedchannel flow between approximate results andexperimental ones from Gerhart, et al (1985)

\subsection{Abruptly Expanded Channel Flow}

1. The analytical results on the coefficients of head loss for abruptly varied plane flows are derived based on the analytical velocity profiles with one-dimensional Navier-Stoke's equation. Good trends were obtained after comparing the analytical results with the results of experimental or numerical methods.

2. The abruptly expanded channel flow can be used together with the spillway or sluice gate to quickly release energy and protect the hydraulic structure. Generally speaking, the flow situations of 2-DV and 2-DH can always be linked to achieve the hydraulically protecting purpose.

\section{References}

[1] Rastogi A. K., Rodi W. (1978), Predictions of Heat and Mass Transfer in Open Channels, J. of the Hydraulics Division, ASCE, 104(3), 397-420.

[2] Chen Y.-S., Kim S.-M. (1987), Computation of Turbulent Flows using an Extended k- $\boldsymbol{\varepsilon}$ " Turbulence Closure Model, CR-179204, NASA, p. 21.

[3] Yakhot V., Orszag S. A., Thangam S., Gatski T. B., Speziale C. G. (1992), Development of Turbulence Models for Shear Flows by a Double Expansion Technique, Phys. Fluids A, $4(9)$.
[4] Flokstra C. (1977), The Closure Problem for Depth-Average Two Dimensional Flow, Publication No. 190, Delft Hydraulics Laboratory, The Netherlands.

[5] Wu W. (2004), Depth-Averaged 2-D Numerical Modeling of Unsteady Flow and Non-uniform Sediment Transport in Open Channels, accepted for publication by J. of Hydraulic Engineering, ASCE.

[6] Elder J. W. (1959), The Dispersion of Marked Fluid in Turbulent Shear Flow, J. of Fluid Mechanics, Vol. 5, Part 4.

[7] Fischer H. B., List E. J., Koh R. C. Y., Imberger J., Brooks N. H (1979), Mixing in Inland and Coastal Waters, Academic Press, New York.

[8] Shyy W., Thakur S. S., Quyang H., Liu J., Blosch, E. (1997), Computational Techniques for Complex Transport Phenomenon, Cambridge University Press.

[9] Rodi W. (1993), Turbulence Models and Their Aplication in Hydraulics, 3rd Ed., IAHR Monograph, Balkema, Rottedam.

[10] Edward C. R. Luo (2013),"Hydrodynamic characteristics of Gradually Expanded channel Flow". IJHE 2013, 2(3): 35-41

[11] Albertson, M. Dai, Y. B. Jensen, R. A. and Rouse, H. (1948), "Diffusion of submerged jets", Transactions, ASCE, Paper No. 2409.

[12] Zhang, S.(1989), "Use of sudden enlargement for energy dissipation in hydraulic outlet conduits."

[13] Yu Z. S.et al.(2011), "Numerical computations of flow in a finite diverging channel" J. of Zhejiang Univ-Sci A (ApplPhys\&Eng) 2011 11(1).

[14] Gayathri S. et al.(2011)," Global instabilities in diverging channel flows " Theoretical and computational fluid dynamics Vol.25. No. 1-4 pp. 53-64, 2011.

[15] Tran Thuc (1991), “Two-dimensional morphological computations near hydraulic structures". Dissertation No. WA-91-2 Asian Institute of Technology, Bangkok, Thailand.

[16] Gerhart, P.G. and Gross, R. J.(1985),"Fundamentals of fluid mechanics". Addison-Wesley Publishing Company, Inc., Canada,.

[17] Yang C. S. et al.(2010),“ Fluid flow and heat transfer in a horizontal channel with divergent top wall and heat from below ".J. of Heat transfer Vol.132, Issue 8, 2010. 